Doi: http://dx.doi.org/10.1590/1809-4430-Eng.Agric.v39n5errata1/2019

\title{
ERRATUM
}

In the paper "DRYING KINETICS OF THE SLICED PULP OF BIOFORTIFIED SWEET POTATO (Ipomoea batatas L.)", with DOI number: 10.1590/1809-4430-Eng.Agric.v39n2p176181/2019, published in the journal Agricultural Engineering 39 (2):176-181, on the page 176:

Where it reads:

E-mail: diene_gsouza@hotmail.com | ORCID ID: https://orcid.org/0000-0002-2805-5703

It should read:

E-mail: diene_gsouza@hotmail.com | ORCID ID: https://orcid.org/0000-0002-9837-2210

\section{$\overline{\overline{7 b e a}}$}

